\title{
Analisis Kinerja Keuangan Usaha Agrowisata Yoga Barista di Desa Singapadu, Kecamatan Sukawati, Kabupaten Gianyar
}

\author{
I NYOMAN TRI ANANTA WIJAYA, I KETUT SUAMBA, \\ PUTU UDAYANI WIJAYANTI
}

\author{
Program Studi Agribisnis, Fakultas Pertanian, Universitas Udayana \\ Jalan PB. Sudirman Denpasar, 80323 \\ Email: trianantawijaya@gmail.com \\ suamba_unud@yahoo.co.id
}

\author{
Abstract \\ Financial Performance Analysis of Yoga Barista Agrotourism in Singapadu \\ Village, Sukawati District, Gianyar Regency
}

Agrotourism is one type of agribusiness business. All types of businesses need to make financial reports. Yoga Barista Agrotourism is located in Singapadu Village, Sukawati District, Gianyar Regency. This research discusses the financial performance of Yoga Barista Agrotourism using financial ratio analysis and discriminant analysis (Z-score), as well as the constraints faced during the five years period from 2012 until 2016. The constraints faced by Yoga Barista Agrotourism were discussed descriptive-qualitatively which included internal and external constraints. The results of this research were that the ratio analysis showed during the year 2012 until the year 2016, Yoga Barista Agrotourism has a good financial performance. Atlman Zscore model analysis showed that in 2012 the Yoga Barista Agrotourism was categorized into a gray area and 2013 until 2016 was categorized into healthy category. Constraints faced in running the Yoga Barista Agrotourism were internal constraints such as constraints of working hours and services and external constraints such as civet coffee product supply, land conversion and tourist visit season. Yoga Barista Agrotourism could improve financial performance and business health by improving management and improving business performance.

Keywords: constraints, financial performance, Yoga Barista Agrotourism

\section{Pendahuluan}

\subsection{Latar Belakang}

Agrowisata adalah sebuah sistem kegiatan yang terpadu dan terkoordinasi untuk pengembangan pariwisata sekaligus pertanian, dalam kaitannya dengan pelestarian lingkungan, peningkatan kesajahteraan masyarakat petani (Sutjipta, 2001). Agrowisata diberi batasan sebagai wisata yang memanfaatkan objek-objek pertanian (Tirtawinata dan Fachruddin, 1996).

Agrowisata merupakan salah satu jenis usaha agribisnis. Segala jenis usaha perlu melakukan pembuatan laporan keuangan, tak terkecuali usaha agrowisata. Laporan keuangan ini akan sangat bermanfaat bagi usaha. Laporan keuangan 
merupakan bagian dari proses pelaporan keuangan yang lengkap biasanya meliputi neraca, laporan laba rugi, laporan perubahan posisi keuangan yang dapat disajikan dalam berbagai cara (Ikatan Akuntansi Indonesia, 2009). Laporan keuangan dapat digunakan sebagai bahan untuk melihat kinerja keuangan. Kinerja keuangan perusahaan merupakan suatu gambaran tentang kondisi keuangan suatu perusahaan yang dianalisis dengan alat-alat analisis keuangan, sehingga dapat diketahui mengenai baik buruknya keadaan keuangan suatu perusahaan yang mencerminkan prestasi kerja dalam periode tertentu. Hal ini sangat penting agar sumber daya digunakan secara optimal dalam menghadapi perubahan lingkungan (Fahmi, 2011).

Salah satu agrowisata yang sedang berkembang yaitu Agrowisata Yoga Barista yang terletak di Desa Singapadu, Kecamatan Sukawati, Kabupaten Gianyar. Agrowisata ini merupakan agrowisata berbasis modal. Pemilik usaha pada awalnya melihat peluang yang menjanjikan dari usaha industri pariwisata yang disinergikan dengan pertanian, sehingga dibangunlah usaha Agrowisata Yoga Barista pada tahun 2012. Sejak awal berdirinya Agrowisata Yoga Barista, pihak pengelola sudah mulai membuat laporan keuangan pada umumnya seperti neraca dan laporan laba rugi. Laporan keuangan ini merupakan hal penting dalam dunia usaha. Banyak pihak yang memerlukan informasi terkait kinerja keuangan usaha seperti para kreditur, investor, maupun masyarakat pada umumnya. Analisis laporan keuangan perlu dilakukan untuk meminimalkan kesalahan dalam mengintepretasikan laporan keuangan. Analisis pada laporan keuangan dapat dilakukan dengan menggunakan analisis rasio. Analisis rasio dilakukan dengan menghitung angka-angka yang ada pada laporan neraca dan laporan laba rugi. Analisis laporan keuangan menggunakan analisis rasio masih memiliki kekurangan sehingga perlu dilakukan analisis diskriminan untuk mengklasifikasikan apakah suatu usaha berada pada posisi aman atau tidak. Analisis diskriminan dilakukan dengan memperhitungkan dan menggabungkan beberapa rasio-rasio keuangan tertentu dalam perusahaan dalam suatu persamaan diskriminan yang akan menghasilkan skor tertentu yang akan menunjukkan tingkat kemungkinan kebangkrutan perusahaan.

Berdasarkan latar belakang tersebut peneliti tertarik untuk melakukan penelitian mengenai kinerja keuangan usaha Agrowisata Yoga Barista. Penelitian ini diharapkan dapat mengetahui bagaimana kinerja keuangan dan kendala yang dihadapi usaha Agrowisata Yoga Barista.

\subsection{Rumusan Masalah}

Sesuai dengan latar belakang yang telah diuraikan, maka yang menjadi rumusan masalah dalam penelitian ini adalah sebagai berikut:

1. Bagaimana kinerja keuangan usaha Agrowisata Yoga Barista di Desa Singapadu, Kecamatan Sukawati, Kabupaten Gianyar bila ditinjau dari rasio likuiditas, solvabilitas, aktivitas, dan profitabilitas dari tahun 2012 sampai dengan tahun 2016 ? 
2. Bagaimana kondisi usaha Agrowisata Yoga Barista di Desa Singapadu, Kecamatan Sukawati, Kabupaten Gianyar bila dianalisis menggunakan analisis diskriminan (Z-score) dari tahun 2012 sampai dengan tahun 2016 ?

3. Kendala-kendala apa sajakah yang dihadapi dalam menjalankan usaha Agrowisata Yoga Barista di Desa Singapadu, Kecamatan Sukawati, Kabupaten Gianyar?

\subsection{Tujuan Penelitian}

Sesuai dengan latar belakang yang telah diuraikan, maka tujuan dari penelitian ini adalah sebagai berikut:

1. Untuk mengetahui kinerja keuangan usaha Agrowisata Yoga Barista di Desa Singapadu, Kecamatan Sukawati, Kabupaten Gianyar jika ditinjau dari rasio likuiditas, solvabilitas, aktivitas, dan profitabilitas dari tahun 2012 sampai dengan tahun 2016.

2. Untuk mengetahui kondisi usaha Agrowisata Yoga Barista di Desa Singapadu, Kecamatan Sukawati, Kabupaten Gianyar bila dianalisis menggunakan analisis diskriminan (Z-score) dari tahun 2012 sampai dengan tahun 2016.

3. Mengetahui kendala-kendala yang dihadapi dalam menjalankan usaha Agrowisata Yoga Barista di Desa Singapadu, Kecamatan Sukawati, Kabupaten Gianyar.

\section{Metode Penelitian}

\subsection{Lokasi dan Waktu Penelitian}

Penelitian ini dilakukan di Agrowisata Yoga Barista Desa Singapadu, Kecamatan Sukawati, Kabupaten Gianyar, Provinsi Bali. Penelitian dilaksanakan Januari hingga Maret 2017. Pemilihan Lokasi penelitian dilakukan dengan sengaja menggunakan metode purposive sampling. Metode purposive yaitu suatu metode penentuan daerah penelitian yang sebelumnya ditentukan atas pertimbanganpertimbangan tertentu.

\subsection{Jenis dan Sumber Data}

Menurut Sugiyono (2008), jenis data yang digunakan dalam penelitian ini yaitu (1) data kualitatif yang menjelaskan gambaran umum Agrowisata Yoga Barista beserta gambar atau foto produk Agrowisata Yoga Barista ataupun kondisi usaha yang dicantumkan secara terlampir sebagai data pendukung dan (2) data kuantitatif yang diperlukan adalah laporan keuangan berupa neraca dan laporan laba rugi. Sumber data dalam penelitian ini, yaitu (1) data primer bersumber dari Bapak Ketut Pramana selaku pemilik usaha, Bapak Nengah Susena selaku manajer, dan Bapak Nyoman Samiarta selaku bagian keuangan serta (2) data sekunder diperoleh dari sumber-sumber usaha Agrowisata Yoga Barista, sumber-sumber pustaka yang relevan dan penjelajahan internet sesuai dengan pembahasan penelitian. 


\subsection{Informan Kunci}

Informan penelitian adalah orang yang dimintai atau seseorang yang memiliki informasi (data) tentang situasi dan kondisi latar belakang penelitian (Moleong, 2004). Penentuan respoden dilakukan dengan teknik purposive, dimana informan dipilih secara sengaja dengan mempertimbangkan bahwa informan merupakan orang yang mengetahui secara mendalam tentang usaha Agrowisata Yoga Barista, yaitu pihak pengelola, diantaranya Bapak Ketut Pramana selaku pemilik usaha, Nyoman Samiarta selaku bagian keuangan, dan Nengah Susena selaku manajer.

\subsection{Metode Pengumpulan Data}

Metode pengumpulan data dilakukan dengan (1) Library research, adalah metode pengumpulan data penelitian yang dilakukan dengan cara membaca literatur atau kajian pustaka, catatan-catatan, laporan-laporan laba rugi, dan neraca keuangan agrowisata Yoga Barista dan (2) Field research, adalah metode pengumpulan data yang diperoleh secara langsung dari lapangan, dilakukan dengan pengamatan (observation), yaitu pengamatan langsung terhadap objek di lokasi penelitian dan wawancara mendalam (indepth interview), yaitu proses mencari informasi yang dilakukan dengan tatap muka (face to face) antara pewawancara dengan responden atau narasumber, dengan instrumen penelitian, yaitu pedoman wawancara (guide).

\subsection{Variabel Penelitian dan Pengukuran}

Variabel penelitian dalam penelitian ini adalah rasio likuiditas diantaranya, yaitu rasio lancar, dan rasio kas. Rasio solvabilitas diantaranya yaitu, rasio utang terhadap aset, rasio utang terhadap modal, rasio utang jangka panjang terhadap modal, rasio kelipatan bunga yang dihasilkan, dan rasio laba operasional terhadap kewajiban. Rasio aktifitas diantaranya yaitu, rasio perputaran persediaan, rasio perputaran modal kerja, rasio perputaran aset tetap, dan rasio perputaran total aset. Rasio profitabilitas diantaranya yaitu, rasio hasil pengembalian atas aset, rasio hasil pengembalian atas ekuitas, rasio marjin laba kotor, rasio marjin laba operasional, dan rasio marjin laba bersih. Analisis diskriminan (Z-score) dan kendala-kendala dalam menjalankan usaha Agrowisata Yoga Barista.

\subsection{Metode Analisis Data}

Metode analisis data yang digunakan dalam penelitian ini ada dua macam, yaitu (1) analisis deskriptif kualitatif mengulas atau mendeskripsikan gambaran umum usaha Agrowisata Yoga Barista dan (2) analisis deskriptif kuantitatif menggunakan analisis rasio keuangan dan analisis diskriminan (Z-score).

\section{Hasil dan Pembahasan}

\subsection{Analisis Rasio}

Kinerja keuangan Agrowisata Yoga Barista dianalisis menggunakan analisis rasio. Teknik analisis ini dilakukan dengan membandingkan masing-masing pos 
laporan keuangan yang relevan atau data yang signifikan dimana terdapat empat rasio yang digunakan diantaranya yaitu, rasio likuiditas, rasio solvabilitas, rasio aktivitas, dan rasio profitabilitas (Hery, 2016). Hasil analisis rasio keuangan Agrowisata Yoga Barista adalah sebagai berikut.

\subsubsection{Rasio likuiditas}

Berdasarkan hasil analisis rasio, kedua rasio likuiditas Agrowisata Yoga Barista tahun 2012 s.d. 2016 mengalami perkembangan yang berfluktuasi. Hasil analisis dapat dilihat pada Tabel 1 .

Tabel 1.

Rasio Likuiditas Agrowista Yoga Barista Tahun 2012 s.d. 2016

\begin{tabular}{lrrrrr}
\hline \multirow{2}{*}{ Rasio Likuiditas } & \multicolumn{5}{c}{ Tahun } \\
\cline { 2 - 6 } & 2012 & 2013 & 2014 & 2017 & 2016 \\
\hline Rasio Lancar & 4,20 & 6,90 & 7,02 & 5,38 & 5,52 \\
\hline Rasio Kas & 0,26 & 0,46 & 0,32 & 0,43 & 0,50 \\
\hline
\end{tabular}

Sumber: diolah dari data primer

Rasio lancar selama lima tahun terus menunjukkan hasil di atas 1, yang berarti Agrowisata Yoga Barista mampu untuk membayar kewajiban lancar menggunakan aset lancar yang dimiliki setiap tahunnya. Rasio kas berada di bawah 1, yang artinya jika hanya mengandalkan kas, Agrowisata Yoga Barista kurang mampu membayar kewajiban lancar yang dimiliki. Secara umum, Agrowisata Yoga Barista sudah bisa dikatakan likuid, dimana seluruh aset lancar yang dimiliki sudah mampu digunakan untuk membayar kewajiban lancar.

\subsubsection{Rasio solvabilitas}

Berdasarkan hasil analisis rasio likuiditas, dari lima rasio yang digunakan, empat rasio terus mengalami perbaikan hasil, hanya satu rasio yang perkembangannya berfluktuasi. Rasio solvabilitas Agrowisata Yoga Barista tahun 2012 s.d. 2016 dapat dilihat pada Tabel 2.

Tabel 2.

Rasio Solvabilitas Agrowisata Yoga Barista tahun 2012 s.d. 2016

\begin{tabular}{lrrrrr}
\hline \multirow{2}{*}{ Rasio Solvabilitas } & \multicolumn{5}{c}{ Tahun } \\
\cline { 2 - 6 } & 2012 & 2013 & 2014 & 2017 & 2016 \\
\hline Rasio Utang Terhadap Aset & 0,42 & 0,30 & 0,21 & 0,21 & 0,18 \\
\hline Rasio Utang Terhadap Modal & 0,71 & 0,43 & 0,27 & 0,26 & 0,22 \\
\hline Rasio Utang Jangka Panjang Terhadap Modal & 0,45 & 0,28 & 0,13 & 0,08 & 0,04 \\
\hline Rasio Kelipatan Bunga yang Dihasilkan & 22,77 & 49,73 & 80,86 & 73,74 & 78,16 \\
\hline Rasio Laba Operasional Terhadap Kewajiban & 0,25 & 0,55 & 0,89 & 0,97 & 1,25 \\
\hline
\end{tabular}

Sumber: diolah dari data primer 
Rasio utang terhadap aset, rasio utang terhadap modal, dan rasio utang jangka panjang terhadap modal, jika menunjukkan rasio yang kecil berarti semakin sedikit usaha Agrowisata Yoga Barista dibiayai oleh utang, sehingga semakin kecil rasio maka semakin baik. Rasio utang terhadap aset, rasio utang terhadap modal, dan rasio utang jangka panjang terhadap modal selalu menunjukkan hasil lebih kecil dari 1 , yang berarti dalam pembiayaan usaha Agrowisata Yoga Barista selama lima tahun selalu lebih banyak bersumber dari modal sendiri dan sedikit bersumber dari utang. Perolehan rasio utang terhadap aset, rasio utang terhadap modal, dan rasio utang jangka panjang terhadap modal yang semakin kecil menunjukkan bahwa setiap tahunnya Agrowisata Yoga Barista selalu menambah modal sendiri dan menurunkan utang yang dimiliki. Rasio kelipatan bunga yang dihasilkan menunjukkan pekembangan yang berfluktuasi dikarenakan jumlah pinjaman di bank selalu berubah setiap tahunnya, tergantung dari kebutuhan dana yang diperlukan untuk menunjang usaha. Rasio laba operasional terhadap kewajiban terus mengalami kenaikan, dimana kemampuan Agrowisata Yoga Barista untuk membayar kewajiban menggunakan laba operasional terus membaik.

\subsubsection{Rasio aktivitas}

Hasil analisis rasio aktivitas menunjukkan rasio perputaran persediaan dan perputaran modal kerja perkembangannya berfluktuasi, sedangkan rasio perputaran aset tetap dan perputaran total aset terus mengalami kenaikan. Hasil perhitungan rasio aktivitas Agrowisata Yoga Barista tahun 2012 s.d. 2016 dapat dilihat pada Tabel 3.

Tabel 3.

Rasio Aktivitas Agrowisata Yoga Barista Tahun 2012 s.d.20116

\begin{tabular}{lrrrrr}
\hline \multicolumn{1}{c}{ Rasio Aktivitas } & \multicolumn{6}{c}{ Tahun } \\
\cline { 2 - 6 } & 2012 & 2013 & 2014 & 2017 & 2016 \\
\hline Rasio Perputaran Persediaan & 10,56 & 11,07 & 10,54 & 10,75 & 10,98 \\
\hline Rasio Perputaran Modal Kerja & 1,88 & 1,98 & 1,94 & 1,94 & 2,01 \\
\hline Rasio Perputaran Aset Tetap & 3,40 & 4,98 & 5,95 & 6,34 & 7,26 \\
\hline Rasio Perputaran Total Aset & 1,21 & 1,41 & 1,46 & 1,49 & 1,57 \\
\hline
\end{tabular}

Sumber: diolah dari data primer

Rasio perputaran persediaan jika dirata-ratakan akan memperoleh nilai 10,78, atau dengan kata lain lamanya rata-rata persediaan terjual adalah 34 hari. Rasio perputaran modal perkembangannya sedikit berfluktuasi. Rasio perputaran aset tetap, rasio perputaran total aset terus mengalami peningkatan. Agrowisata Yoga Barista secara keseluruhan telah menjalankan usahanya dengan baik, dimana modal kerja, aset tetap dan total aset yang dimiliki telah mampu dimanfaatkan dengan lebih baik setiap tahunnya. 


\subsubsection{Rasio profitabilitas}

Selama lima tahun, rasio profitabilitas menunjukkan hasil yang membaik. Rasio profitabilitas Agrowisata Yoga Barista tahun 2012 s.d. 2016 dapat dilihat pada Tabel 4.

Tabel 4.

Rasio Profitabilitas Agrowisata Yoga Barista tahun 2012 s.d. 2016

\begin{tabular}{lrrrrr}
\hline \multirow{2}{*}{ Rasio Profitabilitas } & \multicolumn{5}{c}{ Tahun } \\
\cline { 2 - 6 } & 2012 & 2013 & 2014 & 2017 & 2016 \\
\hline Rasio Hasil Pengembalian Atas Aset & 0,07 & 0,13 & 0,15 & 0,15 & 0,19 \\
\hline Rasio Hasil Pengembalian Atas Ekuitas & 0,12 & 0,18 & 0,19 & 0,19 & 0,23 \\
\hline Rasio Marjin Laba Kotor & 0,58 & 0,58 & 0,58 & 0,59 & 0,60 \\
\hline Rasio Marjin Laba Operasional & 0,09 & 0,12 & 0,13 & 0,13 & 0,14 \\
\hline Rasio Marjin Laba Bersih & 0,06 & 0,09 & 0,10 & 0,10 & 0,12 \\
\hline
\end{tabular}

Sumber: diolah dari data primer

Perolehan setiap rasio profitabilitas menunjukkan sedikit kenaikkan setiap tahunnya, namun dapat dikatakan Agrowisata Yoga Barista sudah menjalankan aktivitas normal bisnisnya dengan baik, dimana Agrowisata Yoga Barista mampu mempertahankan dan meningkatkan perolehan laba usaha selama lima tahun usaha berdiri.

\subsection{Analisis Diskriminan Model Altman (Z-Score)}

Analisis diskriminan merupakan suatu analisis untuk mengatasi kekurangan analisis rasio yang dapat digunakan untuk mengklasifikasikan suatu perusahaan apakah berada pada posisi bangkrut, sehat atau grey area (Darsono dan Ashari, 2004). Usaha yang mempunyai skor $Z$ lebih besar dari 2,99 diklasifikasikan sebagai usaha sehat, sedangkan usaha yang mempunyai skor $\mathrm{Z}$ lebih kecil dari 1,81 diklasifikasikan sebagai usaha potensial bangkrut dan skor 1,81 sampai 2,99 diklasifikasikan sebagai usaha pada grey area atau daerah kelabu (Muslich, 2000). Hasil perhitungan Z-score usaha Agrowisata tahun 2012 s.d. 2016 dapat dilihat pada Tabel 5.

Tabel 5.

Z-Score Usaha Agrowisata Yoga Barista Tahun 2012 s.d. 2016

\begin{tabular}{ccc}
\hline Tahun & Z-Score & Keterangan \\
\hline 2012 & 2.89 & Grey Area \\
2013 & 3.82 & Sehat \\
2014 & 4.56 & Sehat \\
2015 & 4.66 & Sehat \\
2016 & 5.07 & Sehat \\
\hline
\end{tabular}

Sumber: diolah dari data primer

Z-score usaha Agrowisata Yoga Barista pada tahun 2012 menunjukkan skor 2,89 dimana skor berada di antara 1,81 sampai 2,99 yang artinya usaha berada pada 
posisi grey area. Z-score tahun 2013 mengalami peningkatan menjadi 3,82 dimana skor berada di atas 2,99 yang artinya usaha berada dalam posisi sehat. Z-score tahun 2014 mengalami peningkatan menjadi 4,56 dimana skor berada di atas 2,99 yang artinya usaha berada dalam posisi sehat. Z-score tahun 2015 mengalami peningkatan menjadi 4,66 dimana skor berada di atas 2,99 yang artinya usaha berada dalam posisi sehat. Z-score tahun 2016 mengalami peningkatan menjadi 5,07 dimana skor berada di atas 2,99 yang artinya usaha berada dalam posisi sehat.

\subsection{Kendala-Kendala dalam Menjalankan Agrowisata Yoga Barista}

Menurut Hansen dan Mowen (2000), berdasarkan asalnya jenis kendala dapat dikelompokkan menjadi kendala internal dan kendala eksternal. Agrowisata Yoga Barista selama ini telah berjalan dengan baik, namun berdasarkan hasil wawancara, dalam menjalankan usaha agrowisata Yoga Barista selama ini mengalami beberapa kendala diantaranya:

1. Kendala internal, yaitu kendala terkait jam kerja, dimana seluruh tenaga kerja bergagama Hindu dan sebagian besar sudah menikah. Banyaknya upacara keagamaan membuat agrowisata Yoga Barista harus menurunkan jam operasional usaha pada hari-hari keagamaan dan memberi cuti kepada tenaga kerja yang memiliki kesibukan terkait upacara keagamaan. Kendala lainnya yaitu, kendala pelayanan, dimana tenaga kerja berasal dari latar pendidikan yang berbeda, sehingga menimbulkan adanya perbedaan kualitas pelayanan yang mampu diberikan, salah satunya terkait bahasa asing, dimana tidak semua tenaga kerja mampu berbahasa asing dengan baik.

2. Kendala eksternal, diantaranya yaitu supply produk dari pihak distributor ke agrowisata Yoga Barista, dimana agrowisata Yoga Barista menjual produk utama berupa kopi luwak. Produksi dari kopi luwak ini biasanya tidak stabil mengingat luwak pada umumnya tidak mengkonsumsi kopi sebagai makanan utamanya, hal ini berpengaruh ke produksi kopi luwak yang tidak menentu dan mengakibatkan supply produk kopi luwak ke agrowisata Yoga Barista terkadang mengalami masalah. Kendala lainnya yaitu, alih fungsi lahan, dimana agrowisata Yoga Barista dalam menjalankan usahanya mengandalkan pemandangan berupa hamparan sawah, sehingga alih fungsi lahan dari persawahan menjadi bangunan perumahan dapat menurunkan keunggulan yang dimiliki oleh agrowisata Yoga Barista. Terdapat pula kendala musim, dimana kunjungan wisatawan biasanya dipengaruhi oleh musim, kunjungan wisatawan biasanya lebih banyak terjadi pada musim panas dan cenderung menurun pada musim hujan.

\section{Simpulan dan Saran}

\subsection{Simpulan}

Berdasarkan hasil analisis dan pembahasan yang telah dilakukan, maka dapat disimpulkan, usaha Agrowisata Yoga Barista memiliki kinerja keuangan yang baik dilihat dari rasio likuiditas, solvabilitas, aktivitas, dan profitabilitas. Analisis Z-score 
model Atlman menunjukkan nilai yang semakin membaik setiap tahunnya dimana Zscore pada tahun 2012 dikategorikan dalam grey area dan tahun 2013 s.d. 2016 dikategorikan dalam kategori sehat. Kendala-kendala yang dihadapi dalam menjalankan usaha Agrowisata Yoga Barista adalah kendala internal berupa kendala jam kerja dan pelayanan serta kendala eksternal berupa supply produk kopi luwak, alih fungsi lahan dan musim kunjungan wisatawan.

\subsection{Saran}

Berdasarkan hasil pembahasan dan kesimpulan yang diperoleh maka saran yang dapat disampaikan dalam penelitian ini, yaitu Agrowisata Yoga Barista dapat meningkatkan kinerja keuangan dan kesehatan usaha dengan memperbaiki manajemen dan meningkatkan kinerja usaha. Agrowisata Yoga Barista sebaiknya memperkuat komunikasi dalam menjalankan usaha, mengatur jam kerja serta meningkatkan pelayanan melalui pelatihan. Agrowisata Yoga Barista juga perlu mengatasi masalah supply produk kopi luwak dengan memesan produk kopi luwak dari tempat lain bila terjadi kekurangan produk.

\section{Ucapan Terimakasih}

Ucapan terimakasih ini penulis tunjukan kepada pihak pengelola Agrowisata Yoga Barista dan seluruh pihak yang telah membantu dalam pelaksanaan penelitian hingga karya ilmiah ini dapat dipublikasikan di e-jurnal.

\section{Daftar Pustaka}

Darsono dan Ashari. 2004. Pedoman Praktis Memahami Laporan Keuangan. Semarang: Andi.

Fahmi, Irham. 2011. Analisis Laporan Keuangan. Lampulo: Alfabeta.

Hansen Don R, Maryanne M. Mowen. 2000. Akuntansi Manajemen, Edisi Kedua, terjemahan: A. Hermawan, Jakarta: Erlangga.

Hery. 2016. Analisis Laporan Keuangan. Jakarta: Gramedia Widiasarana Indonesia.

Ikatan Akuntansi Indonesia. 2009. Standar Akuntansi Keuangan. Jakarta: Salemba Empat.

Moleong, L. J. 2004. Metodologi Penelitian Kualitatif, Bandung: PT Remaja Rosdakarya.

Muslich, Mohamad. 2000. Manajemen Keuangan Modern (Analisis, Perencanaan, dan Kebijaksanaan). Jakarta: Bumi Aksara.

Sugiyono. 2008. Metodologi Penelitian Kuantitatif Kualitatif dan $R \& D$. Bandung: Alfabeta.

Sutjipta, Nyoman. 2001. Agrowisata. Denpasar: Magister Manajemen Agribisnis Universitas Udayana Bali.

Tirtawinata, M.R. dan L. Fachruddin. 1996. Daya Tarik dan Pengelolaan Agrowisata. Jakarta: Penebar Swadaya. 